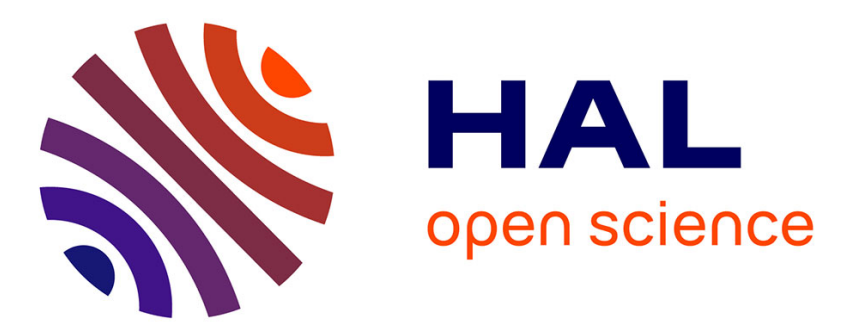

\title{
A new meta-model to calculate carbonation front depth within concrete structures
}

Van-Loc Ta, Stéphanie Bonnet, Tristan Senga Kiessé, Anne Ventura

\section{To cite this version:}

Van-Loc Ta, Stéphanie Bonnet, Tristan Senga Kiessé, Anne Ventura. A new meta-model to calculate carbonation front depth within concrete structures. Construction and Building Materials, 2016, 129, pp.172-181. 10.1016/j.conbuildmat.2016.10.103 . hal-01602476

\section{HAL Id: hal-01602476 https://hal.science/hal-01602476}

Submitted on 13 Dec 2017

HAL is a multi-disciplinary open access archive for the deposit and dissemination of scientific research documents, whether they are published or not. The documents may come from teaching and research institutions in France or abroad, or from public or private research centers.
L'archive ouverte pluridisciplinaire HAL, est destinée au dépôt et à la diffusion de documents scientifiques de niveau recherche, publiés ou non, émanant des établissements d'enseignement et de recherche français ou étrangers, des laboratoires publics ou privés.

$$
\text { Copyright }
$$




\title{
A new meta-model to calculate carbonation front depth within concrete structures
}

\author{
Van-Loc Ta ${ }^{\mathrm{a}, *}$, Stéphanie Bonnet ${ }^{\mathrm{b}}$, Tristan Senga Kiesse ${ }^{\mathrm{a}, \mathrm{c}}$, Anne Ventura ${ }^{\mathrm{a}}$ \\ ${ }^{a}$ Université de Nantes, GeM, Institut de Recherche en Génie civil et Mécanique, CNRS UMR 6183, Chaire Génie Civil Eco-construction, France \\ ${ }^{\mathrm{b}}$ Université de Nantes, GeM, Institut de Recherche en Génie civil et Mécanique, CNRS UMR 6183, France \\ ${ }^{\mathrm{c}}$ UMR SAS, INRA, AGROCAMPUS OUEST, 35000 Rennes, France
}

\begin{abstract}
Carbonation processes cannot be ignored as regards durability and service-life of new concrete structures, and their correct understanding and quantification are essential for maintenance and repair works on existing structures. This paper initially presents a new meta-model developed to calculate carbonation front depth based on the analytic solution of Fick's first law. The only input data required by this non numerical model are: (i) material variables (concrete mix design, maximum nominal aggregate size, cement type, and chemical composition of cement type CEM I and cement density); (ii) technological parameters (initial curing period $\left(t_{c}\right)$ ); (iii) environmental parameters (ambient temperature $(T$ ), relative external humidity $(\mathrm{RH})$ and $\mathrm{CO}_{2}$ concentration in the air $\left(\left[\mathrm{CO}_{2}\right]_{\text {ext }}\right)$ ). Consequently, this model is fully suitable for the prediction of carbonation depth in the case of new reinforced concrete structures, for which these required parameters are well-known. The meta-model is validated using data from the literature on short and long-term natural carbonation exposure conditions. Most of the experimental data concern CEM I, CEM II, CEM III cement types, and CEM I additives (fly ash (FA)) with various water to cement $(W / C)$ ratios and $t_{c}$. The meta-model is also compared with two already available models: Papadakis' model and Yang's model. The three model predictions are compared with the corresponding values found in the literature. The results confirm that the prediction of the new meta-model proposed here for estimation of carbonation depth is the most accurate in every case.
\end{abstract}

\section{Introduction}

The corrosion of steel reinforcements is a major cause of the degradation of reinforced concrete (RC) structures. The corrosion of RC structures is due to both to the ingress of chloride ions and to carbonation. It is considered as a two-stage process: (i) corrosion initiation stage; and (ii) corrosion propagation stage [1]. Carbonation is a widespread degradation of concrete, which can be coupled with more severe deteriorations [2]. This paper focuses on carbon-

\footnotetext{
* Corresponding author.

E-mail address: van-loc.ta@etu.univ-nantes.fr (V.-L. Ta).
}

\author{
Keywords: \\ Natural carbonation \\ Reinforced concrete \\ Fick's first law \\ Meta-model
}

ation phenomena only: mechanism, influence factors and carbonation modelling.

The carbonation of cementitious materials is caused by carbon dioxide $\left(\mathrm{CO}_{2}\right)$ in the air within a range of 350 up to $380 \mathrm{ppm}$ (parts per million), corresponding to a volume concentration ranging between $0.00057 \mathrm{~kg} / \mathrm{m}^{3}$ and $0.00062 \mathrm{~kg} / \mathrm{m}^{3}$ [3]. $\mathrm{CO}_{2}$ dissolves in the aqueous pore solution and produces carbonic acid $\left(\mathrm{H}_{2} \mathrm{CO}_{3}\right)$. Carbonation is the result of a neutralization reaction between basic compounds of hydrated cement (essentially calcium hydroxide ( $\mathrm{Ca}$ $(\mathrm{OH})_{2}$ ) and calcium-silicate-hydrate $(\mathrm{CSH})$ ) and $\mathrm{H}_{2} \mathrm{CO}_{3}$, producing calcite $\left(\mathrm{CaCO}_{3}\right)$ and water $\left(\mathrm{H}_{2} \mathrm{O}\right)$ [4] [5]. This provokes a drop in $\mathrm{pH}$. The depth of the carbonated cement concrete front increases 
with time. When it reaches the reinforced layer, corrosion is likely to occur because steel bars are not passivated anymore.

Carbonation models have been extensively developed to predict carbonation depth. Currently, available carbonation models have been developed with different approaches and for different cases by underlying, for instance, the influence of the material composition, of the environmental conditions, etc. Many papers discussing the different modelling approaches of carbonation process can be found in the literature. The models can be divided into three main categories:

Empirical [6];

Semi-empirical [3,4,7-12];

Numerical [13-16].

Currently, existing models have limitations that prevent some possible applications for civil engineers as regards life cycle design of RC structures. This is for two main reasons: (i) numerical models are difficult to use because they require accurate and complete data (the number and accuracy of input parameters required are too large and time consuming); (ii) semi-empirical models are quite simple but have generally been developed to match specific application cases, like special additives [9], or influence of initial curing period $\left(t_{c}\right)$ [17].

The aim of this paper is to propose a general model for carbonation, which can be used by civil engineers in as many application cases as possible. This model must be sufficiently accurate, physically and chemically correct, as simple as possible and based on information which is available from the structure design. This approach is based on already existing semi-empirical, a more user-friendly format to civil engineers [18].

This paper initially presents a literature review on studies conducted on semi-empirical models based on the analytic solution of Fick's first law using the diffusion coefficient of $\mathrm{CO}_{2}$ and the amount of $\mathrm{CO}_{2}$ absorbed to predict the carbonation depth of RC structures exposed to given environmental atmospheric conditions.

Then, a simple meta-model to calculate concrete carbonation depth under natural carbonation process based on the analytic solution of Fick's first law is described. This meta-model takes many influencing factors, which were previously considered in separate models like concrete mix design, sand to gravel ratio, maximum aggregate size, cement type, and chemical composition of cement of cement type CEM I and cement density, $t_{c}$, ambient temperature $(T)$, relative external humidity $(R H)$, and $\mathrm{CO}_{2}$ concentration in the air $\left(\left[\mathrm{CO}_{2}\right]_{\text {ext }}\right)$.

Finally, the meta-model is validated using some data on the short and long-term natural carbonation exposure conditions with different water to cement $(W / C)$ ratios, $t_{c}$, and cement types (CEM I, CEM II, CEM III, and CEM I additives (FA)) found in the literature.

\section{Literature review on carbonation models based on the analytic solution of Fick's first law}

\subsection{The analytic solution of Fick's first law}

After a sufficiently long period of time, the carbonation process can be modeled using the scheme presented in Fig. 1 where three zones can be distinguished [19-22]. The first zone, close to the surface exposed to air, is considered fully carbonated: its carbonate content is constant. Then, a transition zone, often referred carbonation front, corresponds to the part of concrete material, for which the level of carbonation gradually decreases form its maximum (at interface with the first zone) to zero, and finally, a third where no carbonation is observed.

Because the carbonation is governed by the diffusion of carbon dioxide within concrete, the square root of time formula is com- monly used for carbonation modelling. The $\mathrm{CO}_{2}$ diffusion model proposed by Klopfer [23] is based on the analytic solution of Fick's first law in the form:

$x_{\mathrm{CO}_{2}}=A \cdot \sqrt{t}$

where: $x_{\mathrm{CO}_{2}}(\mathrm{~m})$ is the carbonation front depth, $t(\mathrm{~s})$ is the exposure time and the carbonation coefficient $A\left(\mathrm{~m} / \mathrm{s}^{1 / 2}\right)$ is determined as:

$A=\sqrt{\frac{2 \cdot D_{\mathrm{CO}_{2}} \cdot\left[\mathrm{CO}_{2}\right]_{e x t}}{a}}$

where: $D_{\mathrm{CO}_{2}}\left(\mathrm{~m}^{2} / \mathrm{s}\right)$ is the $\mathrm{CO}_{2}$-diffusion coefficient in carbonated concrete, $a\left(\mathrm{~kg} / \mathrm{m}^{3}\right)$ is the amount of $\mathrm{CO}_{2}$ absorbed.

Depending on the models were developed, more or less material variables, technological and environmental factors are taken into account. The main models used for prediction are summarized in Table 1.

For some of the models based on the analytic solution of Fick's law, it is assumed that the medium, in which diffusion takes place, does not change over time (homogeneous concrete) and admit the use of a constant diffusion coefficient [8]. However, concretes used in reinforced structures are not ideally homogeneous.

The diffusion of $\mathrm{CO}_{2}$ depends not only on the $\mathrm{CO}_{2}$ concentration gradient but also on the concrete microstructures. This is a substantial simplification of the description of the carbonation process based on Fick's law, which does not take many additional factors discussed below like change in diffusivity as a function of humidity, qualitative and quantitative characteristics of the material composition of concrete (as $W / C$ ratio, type of cement, etc.), technological (as $t_{c}$ ) and environmental factors (as $T, R H$ ) into account.

The amount of $\mathrm{CO}_{2}$ absorbed also affects the carbonation rate. The existing models consider the different expression of $a$ (Table 1).

\subsection{Amount of $\mathrm{CO}_{2}$ absorbed: a $\left(\mathrm{kg} / \mathrm{m}^{3}\right)$}

Papadakis [4], Salvoldi et al. [12] and Bakker [8] show that the constituents of hardened cement paste subjected to carbonation are principally $\mathrm{Ca}(\mathrm{OH})_{2}$ and $\mathrm{CSH}$ in the presence of moisture, and calcium silicates $\left(3 \mathrm{CaO} . \mathrm{SiO}_{2}\right.$ and $\left.2 \mathrm{CaO} . \mathrm{SiO}_{2}\right)$ prior to hydration. From on the chemical reactions of hydration, they develop some mathematical models based on some experimental parameters to determine the molar concentration of the carbonated constituents of the paste per unit volume of concrete.

Yang et al. [11] and Jiang et al. [9] show that the ultimate value of the molar concentration of the constituents, which can potentially be carbonated, highly depends on the concrete cement content. When increasing the amount of cement, the amount of $\mathrm{CO}_{2}$ absorbed increases. Consequently, the molar concentration of the carbonated constituents is directly proportional to the cement content.

\section{3. $\mathrm{CO}_{2}$-diffusion coefficient: $\mathrm{D}_{\mathrm{CO}_{2}}\left(\mathrm{~m}^{2} / \mathrm{s}\right)$}

As already stated, assuming the diffusion coefficient to be constant like in Bakker [8] is not appropriate in this case. In the model proposed by Millington [24], the $\mathrm{CO}_{2}$-diffusion coefficient is calculated as the function of the $\mathrm{CO}_{2}$-diffusion coefficient in the air, the porosity and the concrete saturation level in the form [24]:

$D_{\mathrm{CO}_{2}}=D_{\mathrm{CO}_{2}}^{o} \cdot \phi^{k} \cdot(1-S)^{g}$

where: $D_{\mathrm{CO}_{2}}^{o}\left(\mathrm{~m}^{2} / \mathrm{s}\right)$ is the $\mathrm{CO}_{2}$-diffusion coefficient in the air $\left(1.6 \times 10^{-5}\left(\mathrm{~m}^{2} / \mathrm{s}\right)\right), \phi$ (n.u.) (n.u. = no unit) is the concrete porosity, $S$ (n.u.) is the concrete saturation level or called the internal relative humidity, $k$ and $g$ (n.u.) are empirical constant coefficients $(k=2.74$ and $g=4.20$ ). 


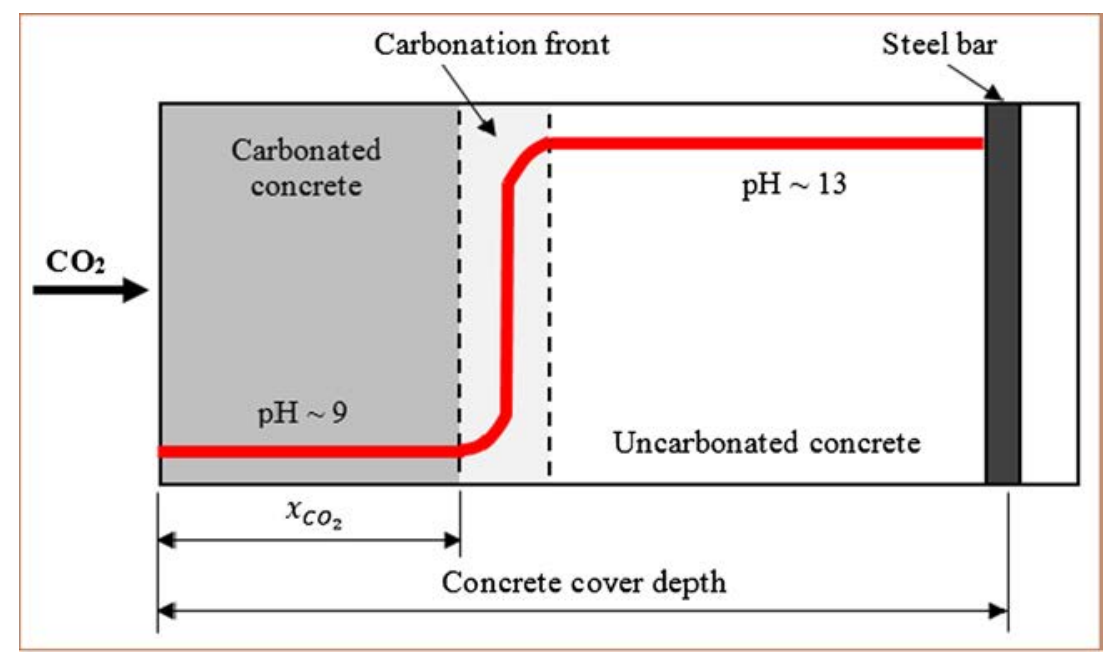

Fig. 1. Drop in $\mathrm{pH}$ in the concrete cover depth due to carbonation.

Table 1

Summary table of simplified carbonation models based on Fick's first law.

\begin{tabular}{|c|c|c|c|}
\hline Amount of $\mathrm{CO}_{2}$ absorbed: $a\left(\mathrm{~kg} / \mathrm{m}^{3}\right)$ & $\mathrm{CO}_{2}$-diffusion coefficient: $D_{\mathrm{CO}_{2}}\left(\mathrm{~m}^{2} / \mathrm{s}\right)$ & Validation & Ref. \\
\hline$a=[C H]$ & $D_{\mathrm{CO}_{2}}=4.8 \times 10^{-7}$ & Accelerated & {$[8]$} \\
\hline$a=[C H]$ & $D_{\mathrm{CO}_{2}}=23.32 D_{\mathrm{CO}_{2}}^{r e f}(1-R H)^{2} R H^{2.6}$ & Accelerated & {$[12]$} \\
\hline$a=0.33 \cdot[\mathrm{CH}]+0.214 \cdot[\mathrm{CSH}]$ & $D_{\mathrm{CO}_{2}}=D_{o}\left(\frac{\phi_{c a r b o n}-\phi_{a i r}}{\frac{W}{\rho_{w}}+\frac{C_{c}}{\rho_{c}}+\frac{F A}{\rho_{f_{a}}}}\right)^{n} \times(1-R H)^{2.2}$ & Accelerated & {$[4][25][27]$} \\
\hline$a=\frac{366.7 \times 10^{-3} t \cdot W}{(2+t) \cdot\left(1-\frac{W}{C}\right)}$ & $D_{\mathrm{CO}_{2}}=158.05 \times 10^{-9} \cdot \beta_{s} \cdot \beta_{f} \cdot(1-R H)^{0.6}\left(\frac{S+G}{C}\right)^{0.1} \cdot \frac{0.1+2.62\left(\frac{W}{C}\right)^{4.2} \cdot t}{1.5 t\left(\frac{W}{C}\right)^{2}}$ & Natural & [11] \\
\hline$a=\Psi\left(1-\frac{\Psi_{f a} \times F A \times A l_{2} O_{3}}{19.06 \times 10^{-3}(1-F A)}\right)$ & $D_{\mathrm{CO}_{2}}=8165472 \times 10^{-11}(1-R H)^{2.2}\left(\frac{W}{C}-0.34\right)$ & Accelerated & [9] \\
\hline \multicolumn{2}{|c|}{$\frac{D_{C O_{2}}}{a}=\left(\frac{1-R H^{5}}{1-0.65^{5}}\right)^{2.5} \cdot\left(\frac{t_{\mathrm{wc}}}{7}\right)^{-0.567} \cdot\left(1.25 R_{A C C, 0}^{-1}+10^{-11}\right) \cdot W_{e}(t)^{2}$} & Accelerated & [3] \\
\hline
\end{tabular}

where:

$[\mathrm{CH}]$ and $[\mathrm{CSH}]\left(\mathrm{kg} / \mathrm{m}^{3}\right)$ are the hydrate and anhydrate contents $\left(\mathrm{C}=\mathrm{CaO}, \mathrm{S}=\mathrm{SiO}_{2}, \mathrm{H}=\mathrm{H}_{2} \mathrm{O}\right)$

$\mathrm{Al}_{2} \mathrm{O}_{3}$ (n.u.) is the amount of $\mathrm{Al}_{2} \mathrm{O}_{3}$ per weight cement;

$D_{\mathrm{CO}_{2}}^{r e f}\left(\mathrm{~m}^{2} / \mathrm{s}\right)$ is the $\mathrm{CO}_{2}$-diffusion coefficient determined with $\mathrm{RH}$ value about 0.58 ;

$\Psi$ (n.u.) is the degree of hydration of cement;

$\Psi_{f a}$ (n.u.) is the degree of hydration of fly ash;

$D_{o}\left(\mathrm{~m}^{2} / \mathrm{s}\right)$ and $n$ (n.u.) are constant depending on $W / C$ ratio;

$\beta_{s}$ (n.u.) is the correction factor for substitution of supplementary cementitious materials;

$\beta_{f}$ (n.u.) is the correction factor for finishing materials on concrete surface.

Other parameters are defined in the main text.

During natural carbonation, the concrete drying rate is supposed to be higher than the carbonation rate and the internal relative humidity will reach a steady state with the external relative humidity on a time-averaged basis [12]. Based on that assumption, many studies $[9,11,14,25,26]$ suggest that $R H$ can be used as the concrete saturation degree $(R H=S)$.

Considering Table 1 , we found that the models of $\mathrm{CO}_{2}$-diffusion coefficient in concrete are based on Eq. (3). Some authors, moreover, have added some material variables and some technological and environmental factors: Papadakis' model [4,25,27], for example, takes the decreasing in the concrete porosity due to carbonation into account. In Fib [3], a complex model, where many effects are considered (as $t_{c}, R H$ and the weather function $\left(W_{e}(t)\right)$ ). Jiang's model [9] takes the high-volume of fly ash content in concrete into account. Yang's model [11] introduces correction factors by considering not just the substitution of supplementary cementitious materials, the finishing materials but the exposure time also.

\subsection{Conclusion: needs for a new meta-model}

This literature review has been carried out according to the different factors affecting carbonation process. They can be classified as internal or external. The internal factors are: (i) concrete compounds like cement type [10], maximum aggregate size (S_max) [28] (ii) concrete composition like sand to gravel ratio $(S / G)[28]$, $W / C$ ratio $[4,5,29-33]$, cement content $[5,32,34]$, and mineral admixture $[9,27,29,32,35-43]$, (iii) concrete properties like porosity and $\mathrm{CO}_{2}$ diffusivity $[26,44]$. The external factors are: (i) environment like $\left[\mathrm{CO}_{2}\right]_{\text {ext }}[45], T[13,20,21,45,46], R H[4,47]$, (ii) technology like structure surface condition (crack) [30], $t_{c}[17,48-50]$. This extensive literature review reveals that the rate of carbonation increases with increasing $\left[\mathrm{CO}_{2}\right]_{e x t}, T, W / C$ ratio, S_max, early-aged crack width. However, the rate of carbonation decreases with the increase of the 28-day compressive strength $\left(f_{c}\right), t_{c}, S / G$ ratio and cement content. The highest carbonation rates are observed for $R H$ values between $55 \%$ and $75 \%$. The incorporation of FA or ground granulated blast furnace slag (GGBFS) in ordinary Portland cement (CEM I) both decreases carbonation resistance of RC structures, though at significantly different levels. The carbonation resistance of RC structures with GGBFS is better than RC structures with FA [43]. The present study concentrates on FA admixture mixed with CEM I only.

The carbonation models presented in Table 1 consider some of these factors, but none of them include them all. None of the 
models into account the influence of $T$ whereas only Fib's model [3] takes into account the effect of $t_{c}$, for instance. However, in order to use this model to predict the depth of carbonation under natural condition, an accelerated laboratory test is necessary to determine the carbonation resistance $\left(R_{A C C, 0}^{-1}\right)$ [3].

Most of the models presented in Table 1 have been validated using some experimental results obtained with accelerated carbonation laboratory tests. The carbonation depths have been measured on the local concrete used. Fib [3] indicates that the carbonation rate obtained with accelerated carbonation is lower than the natural carbonation one. Consequently, these models may not be used for the accurate prediction of the carbonation depth under natural conditions taking all the influencing parameters into account. Therefore, a meta-model to calculate carbonation front depth by using only technological parameters as inputs (as concrete mixtures, cement type, chemical composition of cement type CEM I, cement density and $t_{c}$ ) and environmental parameters (as $\mathrm{T}, \mathrm{RH}$ and $\left[\mathrm{CO}_{2}\right]_{\text {ext }}$ ) is proposed in the second part of this article. This model, is contrast, takes many important factors influencing the carbonation process into account. Finally, the model is validated using some experimental results obtained under natural carbonation conditions.

\section{Meta-model}

A new generic model built upon several already available specific models is presented. It is specifically developed to suit any situation by improving some of the former model relationships. That is why we call it "meta-model".

The assumptions/simplifications are made to develop the metamodel:

1) Carbonation is modeled as a sharp carbonation front moving inwards [51].

2) Carbonation is controlled by the $\mathrm{CO}_{2}$-diffusion under steady state [45], i.e. the reaction of dissolved $\mathrm{CO}_{2}$ is much faster than the $\mathrm{CO}_{2}$-diffusion process [51].

3) The amount of $\mathrm{CO}_{2}$ absorbed per volume of concrete is determined as the required amount of $\mathrm{CO}_{2}$ gas for making completely carbonated concrete [52], i.e. it is used only for natural carbonation conditions and not for accelerated testing environment [45].

Fig. 2 displays the logic diagram of the developed model. The following sub-section of this part presents a detailed discussion of the fundamental choices and transformations of the equations used in the meta-model.

\subsection{Calculation of the amount of $\mathrm{CO}_{2}$ absorbed: $a\left(\mathrm{~kg} / \mathrm{m}^{3}\right)$}

Pade and Guimaraes [52] have shown that $75 \%$ of the original $\mathrm{CaO}$ in the Portland cement clinker changes into calcium carbonated concrete. Thus, considering the cement paste concrete can be assumed completely carbonated. the amount of $\mathrm{CO}_{2}$ absorbed per volume of completely carbonated concrete is given by [52]:

$a=0.75 \times \mathrm{C} \times \mathrm{CaO} \times \frac{\mathrm{M}_{\mathrm{CO}_{2}}}{\mathrm{M}_{\mathrm{CaO}}}$

where: $C\left(\mathrm{~kg} / \mathrm{m}^{3}\right)$ is the cement content, $\mathrm{CaO}$ (n.u.) is the amount of calcium oxide per weight of cement, $M_{\mathrm{CO}_{2}}$ and $M_{\mathrm{CaO}}(\mathrm{g} / \mathrm{mol})$ are the molar weight of $\mathrm{CO}_{2}$ and $\mathrm{CaO}$ respectively.

Eq. (4) was established for Portland cement (CEM I) including the highest clinker and $\mathrm{CaO}$ content (from $95 \%$ to $100 \%$ for clinker with an average $\mathrm{CaO}$ content of 65\%) [52]. The literature review reveals that, the increases in clinker content in cement generally increases the amount of $\mathrm{CO}_{2}$ absorbed [56] [10]. Natural carbona- tion tests have been conducted by Hyvert et al. [10] for mortars with a $W / C$ ratio 0.5 on different types of cement like CEM I $52.5 \mathrm{~N}$, CEM II A/L $52.5 \mathrm{~N}$, and CEM III A $42.5 \mathrm{~N}$ containing 97.5\%, $87 \%$, and $56 \%$ of clinker, respectively. The results obtained show that the carbonation rate of CEM I is the lowest, followed by CEM II and CEM III.

Thus, in order to consider the different cement types corresponding to various clinker and $\mathrm{CaO}$ contents [53], we introduce the cement clinker content into Eq. (4) to obtain the amount of $\mathrm{CO}_{2}$ absorbed as:

$a=0.75 \times \varphi_{\text {clinker }} \times C \times \mathrm{CaO} \times \frac{\mathrm{M}_{\mathrm{CO}_{2}}}{\mathrm{M}_{\mathrm{CaO}}}$

where: $\varphi_{\text {clinker }}$ (n.u.) is the cement clinker content.

\subsection{Calculation of $\mathrm{CO}_{2}$-diffusion coefficient: $\mathrm{D}_{\mathrm{CO}_{2}}\left(\mathrm{~m}^{2} / \mathrm{s}\right)$}

In the meta-model, the diffusion coefficient is determined by introducing some functions, which depend on the parameters influencing the carbonation process, as:

$D_{\mathrm{CO}_{2}}=D_{\mathrm{CO}_{2}}^{28} \times f(R H) \times f(T) \times f\left(\frac{S+G}{C}\right) \times f\left(\phi, \frac{W}{C}, F A\right) \times f\left(t_{c}\right)$

The expression of those functions is detailed below.

\subsubsection{Function $D_{\mathrm{CO}_{2}}^{28}$}

The function for the $\mathrm{CO}_{2}$ diffusion coefficient in fresh concrete $\left(D_{\mathrm{CO}_{2}}^{28}\right)$ was proposed in [25], which depends on 28-day compressive strength (see Fig. 2). In this study, we introduce the 28-day compressive strength model proposed in [54] into $D_{\mathrm{CO}_{2}}^{28}$ function as shown in Fig. 2.

\subsubsection{Function $f(R H)$}

The $D_{\mathrm{CO}_{2}}^{28}$ function proposed in [25] is only valid for the concrete exposed to the relative external humidity $(R H)$ around $60 \%$. It is thus necessary to modify this expression to account for different values of $R H$. Thus, the function $f(R H)$ was introduced which is selected basing on the long-term experiments in natural conditions where the same concrete was exposed to different $R H$ [12] (see Fig. 2).

\subsubsection{Function $f(T)$}

The function $f(T)$ is used by Arrhenius' law [20]. According to Yan and Jiang [55], we assume that the temperature inside concrete is constant and equal to ambient temperature under natural carbonation (see Fig. 2).

\subsubsection{Function $f((S+G) / C)$}

Basheer et al. [56] indicated that the carbonation depth increases as a result of the increase of aggregate to cement $((S+G) / C)$ ratio $(S=$ Sand and $G=$ Gravel $)$. So, to take this into account, we use an empirical correction term proposed by Yang et al. [11] (see Fig. 2).

\subsubsection{Function $f(\phi, W / C, F A)$}

Concrete with FA has a higher carbonation rate than plain concrete. The impact of FA on the carbonation rate is obviously affected by the $W / C$ ratios. In order to consider the replacement of CEM I by FA into mix concrete and the reduction of concrete porosity due to carbonation [57], Papadakis [27] [58] proposes a functional relationship between the porosity of carbonated concrete, the $W / C$ ratio and the amount of CEM I replaced by FA is given by:

$\left.f\left(\phi_{\text {carbon }}, \frac{W}{C}, F A\right)=\frac{\phi_{\text {carbon }}-\phi_{\text {air }}}{\frac{W}{\rho_{w}}+\frac{C}{\rho_{c}}+\frac{F A}{\rho_{f a}}}\right)^{n}$ 


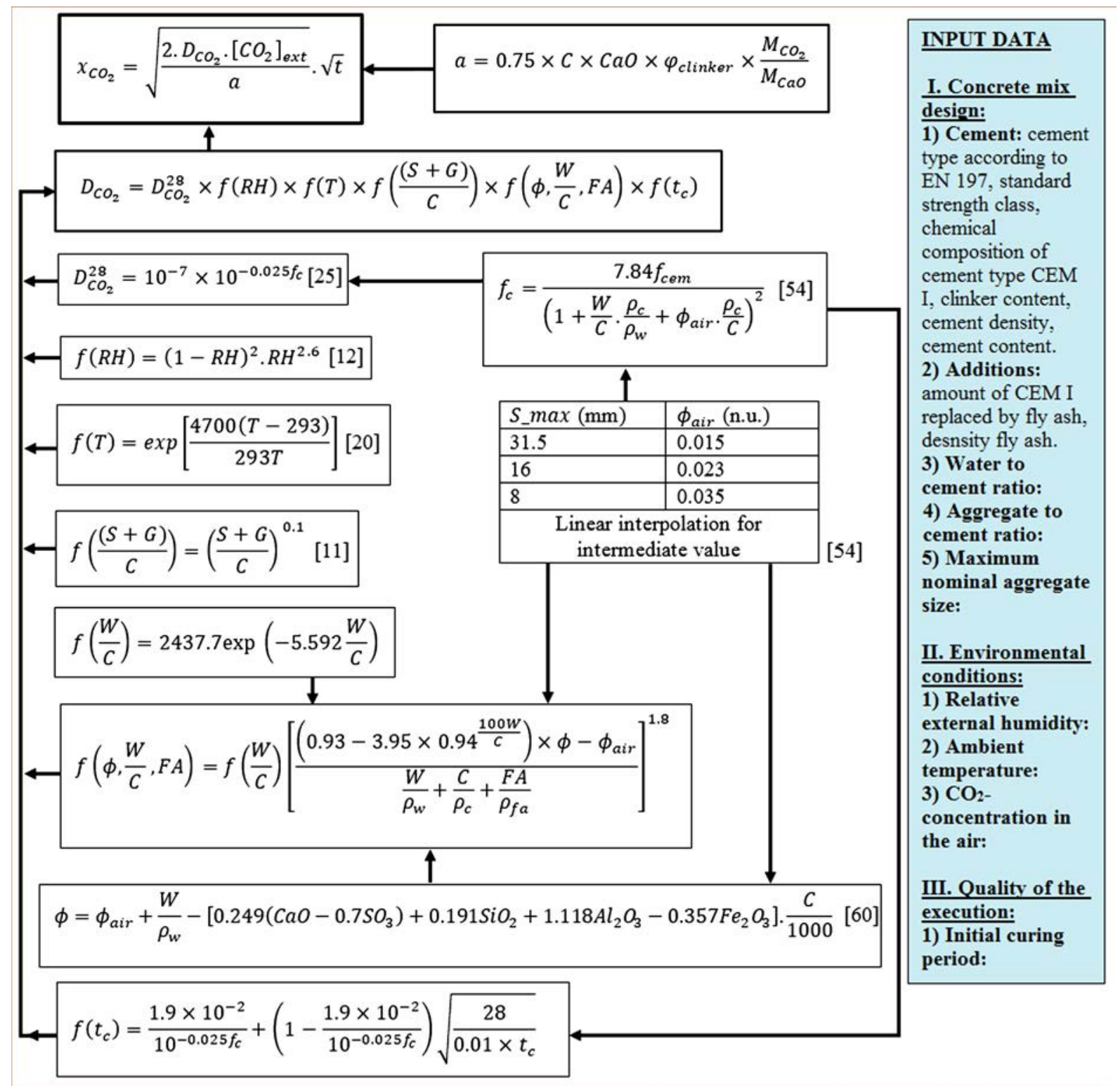

Fig. 2. Meta-model for calculating depth of carbonation front.

where: $\phi_{\text {carbon }}$ (n.u.) is the carbonated concrete porosity, $\phi_{\text {air }}$ (n.u.) is the volume fraction of entrained air into the mix, $W\left(\mathrm{~kg} / \mathrm{m}^{3}\right)$ is the water content of concrete, $F A\left(\mathrm{~kg} / \mathrm{m}^{3}\right)$ is the fly ash content of concrete, $\rho_{w}, \rho_{c}, \rho_{f a}\left(\mathrm{~kg} / \mathrm{m}^{3}\right)$ are the densities of water, cement, and fly ash, respectively, and $n$ (n.u.) is an empirical constant: $n=1.8$ for $0.5<W / C<0.8$.

To account for the effects of $S_{-}$max used in the mix, we use an approximate estimation of $\phi_{\text {air }}$ from $S \_$max proposed by several studies [59] [54]. In this study, we use the values proposed by Papadakis and Demis [54] (see Fig. 2).

From Eq. (7), the expression considering the influence of noncarbonated concrete porosity, the $W / C$ ratio and CEM I + FA contents in concrete, $f(\phi, W / C, F A)$ is established. The solution for $\phi_{\text {carbon }}$ is obtained by combining the function of porosity of carbonated concrete proposed by Park [16] (Eq. (8)) with that of porosity of a concrete with CEM I ( $\phi$ ) proposed by Papadakis [60] (Eq. (9))

$\phi_{\text {carbon }}=\left(0.93-3.95 \times 0.94^{\frac{100 W}{c}}\right) \times \phi$

$$
\phi=\phi_{\text {air }}+\frac{W}{\rho_{w}}-\left[\begin{array}{c}
0.249\left(\mathrm{CaO}-0.7 \mathrm{SO}_{3}\right)+ \\
0.191 \mathrm{SiO}_{2}+1.118 \mathrm{Al}_{2} \mathrm{O}_{3}-0.357 \mathrm{Fe}_{2} \mathrm{O}_{3}
\end{array}\right] \cdot \frac{\mathrm{C}}{1000}
$$

where: $\mathrm{SO}_{3}, \mathrm{SiO}_{2}, \mathrm{Fe}_{2} \mathrm{O}_{3}$ (n.u.) are the amount of sulfur oxide, silicon oxide, iron oxide per weight cement respectively.

For the application of Eq. (7) to $W / C$ ratio $\leqslant 0.5$, a function $f(W / C)$ is introduced. The function values are calculated using experimental data, which were measured at concrete cured of 28-day, by Balayssac et al. [50] for each $W / C$ ratio with the range $0.48-0.65$ (Fig. 3). The law for $f(W / C)$ is determined using the technique of value fitting as shown in Fig. 3 (with a determination coefficient $R^{2}=0.9849$ ). We obtain:

$f\left(\frac{W}{C}\right)=2437.7 \exp \left(-5.592 \frac{W}{C}\right)$

Finally, the solution for $f(\phi, W / C, F A)$ is:

with: 


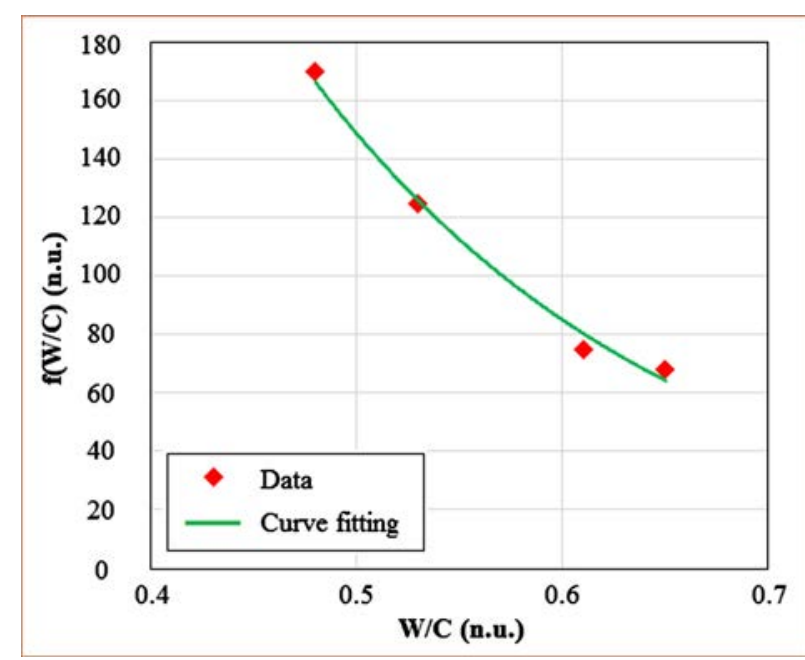

Fig. 3. Normalized data from Balayssac et al. [50] showing $f(W / C)$ versus $W / C$.

$f\left(\phi, \frac{W}{C}, F A\right)=f\left(\frac{W}{C}\right)\left[\frac{\left(0.93-3.95 \times 0.94^{\frac{100 W}{C}}\right) \times \phi-\phi_{a i r}}{\frac{W}{\rho_{w}}+\frac{C}{\rho_{c}}+\frac{F A}{\rho_{f a}}}\right]^{1.8}$

In the particular case of CEM II cement type containing FA, FA value is taken to be zero in Eq. (11) for $[50,61,62]$.

\subsubsection{Function $f\left(t_{c}\right)$}

Fib's model [3], an empirical correction term is introduced to take the effect of $t_{c}$ on the carbonation rate into account. We have:

$f\left(t_{c}\right)=\left(\frac{t_{c}}{7}\right)^{-0.567}$

However, this model does not include the influence of the environmental conditions during curing time (e.g. $T$ and $R H$ ). In this study, the new model proposed allows for this influence of $t_{c}$. Saetta's modelling of the impact of $t_{c}$ take the form [14]:

$f\left(t_{c}\right)=\chi+(1-\chi) \cdot \sqrt{\frac{28}{t_{e}}}$

where: $\chi$ (n.u.) is a constant varying from 0 to 1 and $t_{e}$ (days) is defined as the equivalent curing time. It is a function of $R H$ and $T$.

According to Bazant and Najjar [63] $t_{e}$ is a function of $R H$ and $T$ expressed as:

$d t_{e}=\beta_{R H} \cdot \beta_{T} \cdot d t$

where: $\beta_{R H}$ (n.u.) and $\beta_{T}$ (n.u.) are functions of $R H$ and $T$, respectively.

The expression for $\beta_{R H}$ (n.u.) is given by [63]:

$\beta_{R H}=\left[1+(7.5+7.5 R H)^{4}\right]^{-1}$

$\beta_{T}$ (n.u.) obeys Arrhenius' law and is expressed as [63]:

$\beta_{T}=\exp \left[\frac{E_{a}^{\text {hydration }}}{R}\left(\frac{1}{T_{\text {ref }}}-\frac{1}{T}\right)\right]$

where: $E_{a}^{\text {hydration }}(\mathrm{J} / \mathrm{mol} / \mathrm{K})$ is the hydration activation energy, $R$ $(8.314 \mathrm{~J} / \mathrm{mol} / \mathrm{K})$ is the perfect gas constant, and $T_{\text {ref }}(293 \mathrm{~K})$ is the reference temperature.

Eqs. (13) and (14) can be used in numerical models but not in semi-empirical models. Furthermore, setting the value of constant $\chi$ can be tricky. To solve these problems, a new model taking the impact of $t_{c}$ into account is developed. Eq. (13) is simplified by developing the relationship between $t_{e}$ and $t_{c}$, and setting the constant $\chi$ to a constant value.

The hydration activation energy to gas constant ratio, indeed, here taken to be $2500(\mathrm{~K})$ [63] but depends otherwise on the concrete constituents. Furthermore, concrete tests specimens are generally cured in a temperate room at $20^{\circ} \mathrm{C}$ and with $R H=0.9$ (or 90\%) [63]. By introducing these values into Eqs. (15) and (16), and then by calculating the integral of Eq. (14), the solution obtained takes into account the effect of $t_{c}$ upon carbonation of concrete as:

$f\left(t_{c}\right)=\chi+(1-\chi) \sqrt{\frac{28}{0.01 \times t_{c}}}$

Moreover, Kari's study [64] shows that the constant $\chi$ can be expressed by the ratio of the $\mathrm{CO}_{2}$ diffusion coefficient in water around $1.9 \times 10^{-9} \mathrm{~m}^{2} / \mathrm{s}$ [65] to that in concrete at an age of 28day $\left(D_{\mathrm{CO}_{2}}^{28}\right)$ as shown in Fig. 2. Eq. (17) becomes:

$\left.f\left(t_{c}\right)=\frac{1.9 \times 10^{-2}}{10^{-0.025 f_{c}}}+1-\frac{1.9 \times 10^{-2}}{10^{-0.025 f_{c}}}\right) \sqrt{\frac{28}{0.01 \times t_{c}}}$

\section{Validation and discussions}

In this section, the carbonation depth predicted by the experimental model is compared with results data found in the literature and obtained under natural conditions [2,39,50,61,62,66-70]. These data refer to various short and long-term exposure times. When the chemical composition of cement is not indicated, like in $[50,61,62,66,68-70]$, values are assessed from the VDZ Activity Report [71] and [72].

\subsection{Different initial curing periods}

The meta-model is validated using experimental data found in Balayssac et al. [50]. Where four different concrete types with a $W / C$ ratio of $0.48,0.53,0.61$, and 0.65 , respectively, are considered. After three different $t_{c}$ (1-day, 3-day, and 28-day), they are stored at temperature $20^{\circ} \mathrm{C}$ and humidity of $60 \% \mathrm{RH}$ (with $\left[\mathrm{CO}_{2}\right]_{\text {ext }}$ of $0.03 \%$ or $0.00049 \mathrm{~kg} / \mathrm{m}^{3}$ ) for up to 18 months. For each curing time and each concrete specimen, carbonation depths are measured at 90, 180, 360, and 540 days. Fig. 4 presents the comparison of the experimental carbonation depths with those calculated by the meta-model using a hypothetical line of perfect equality. This line corresponds to the first bisector, on which both calculated and experimental carbonation depths would superimposed perfectly. Most of the experimental data are above the line of equality, which indicates that the predicted carbonation depth values are generally higher than the experimental ones. However, most results are within a $+30 \% /-20 \%$ margin of error. The determination coefficient determined between the 48 plotted points and the line of equality is determined $R^{2}=0.85$. Moreover, among all the models described in Table 1, Fib's model [3], only, takes the effect of $t_{c}$ into account. If we take the carbonation depth after a 28-day curing period as a reference value, the mean ratio of the carbonation depths to the initial curing period (ranging $t_{c}=1$-day and $t_{c}=28$-day, i.e., for $t_{c}=3$-day and 28-day) is determined using Balayssac's data [50], the meta-model and Fib's model for four different $W / C$ ratio (Table 2). The calculated relative errors confirm that the metamodel predictions are more accurate than the Fib's model ones. 


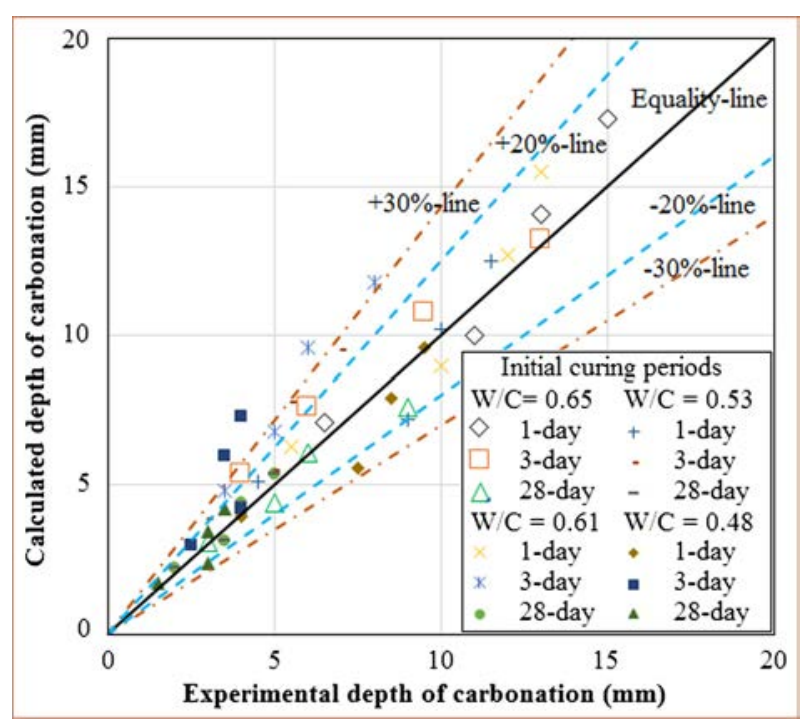

Fig. 4. Comparison between calculated and experimental carbonation depths with different $t_{c}$.

Table 2

Comparison between carbonation depth predictions obtained with the meta-model and Fib's model with different $t_{c}$.

\begin{tabular}{|c|c|c|c|}
\hline & $\begin{array}{l}\text { Balayssac's data } \\
{[50]}\end{array}$ & meta-model & $\begin{array}{l}\text { Fib's model } \\
{[3]}\end{array}$ \\
\hline$r_{1-\text { day }}=\frac{x_{\mathrm{CO}_{2}}\left(t_{c}=1-\text { day }\right)}{x_{\mathrm{CO}_{2}}\left(t_{c}=28-\text { day }\right)}$ & 2.38 & 2.3 & 2.57 \\
\hline Relative error $=\frac{\left|r_{1-d a y}^{e x p}-r_{1-d a y}^{\text {model }}\right|}{r_{1-d a y}^{e x p}}$ & & $3.36 \%$ & $7.98 \%$ \\
\hline$r_{3-\text { day }}=\frac{x_{\mathrm{CO}_{2}}\left(t_{c}=3-\text { day }\right)}{x_{\mathrm{CO}_{2}}\left(t_{c}=28-\text { day }\right)}$ & 1.45 & 1.78 & 1.88 \\
\hline Relative error $=\frac{\left|r_{3-d a y}^{\text {exp }}-r_{3-d a y}^{\text {model }}\right|}{r_{3-d a y}^{\text {exp }}}$ & & $22.75 \%$ & $29.66 \%$ \\
\hline
\end{tabular}

\subsection{Comparison with different experimental data obtained at short} exposure times

A comparison between the meta-model predictions and other experimental results obtained by Rozière et al. [2], Galan et al.
[66], Chatveera et al. [67], Valcuende and Parra [61], Jones et al. [62], De Ceukelaire and Nieuwenburg [70], and Khungthongkeaw et al. [39] is made. A large amount of experimental data on CEM I, CEM II, and CEM III cement types, CEM I + FA with different $W / C$ ratios are collected. The results are presented in Fig. 5. They reveal that, apart from the data by Jones et al. [62] with CEM I $32.5 \mathrm{~N}$ and $W / C=0.59$, which are above a $+20 \%$ margin of error and for which the meta-model overestimates the carbonation depth, most other predictions are within the $\pm 20 \%$ margin of error.

The determination coefficient determined among all the plotted points (65 points) and the line of equality $R^{2}=0.86$. The metamodel predictions are reasonably accurate compared with the experimental data with different $W / C$ ratios, cement types and CEM I + FA with a FA content from 0 up to $50 \%$.

\subsection{Comparison to different $W / C$ ratios at long exposure times}

The reliability of the meta-model, carbonation depth predictions is validated using results measured on actual concrete structure found in the literature [69] (Fig. 6). Carbonation depth results of the models proposed by Papadakis et al. $[4,25,27]$ and Yang et al. [11], are also plotted in the same figure. Papadakis' model tends to underestimate the carbonation depths whereas Yang's one overestimates them. Meta-model predictions, on the other hand, are in good agreement with measurements.

Fig. 7 presents the comparison between the carbonation depth results obtained with the meta-model, Papadakis' model $[4,25,27]$, and Yang's model [11] and those measured on a concrete bridge structure located in Seoul (Korea) [68]. The experimental carbonation depth of this concrete structure is examined after a 18 -year exposure to urban atmospheric conditions. The annual atmosphere concentration of $\mathrm{CO}_{2}$ in Seoul is $355 \mathrm{ppm}$ $\left(0.00058 \mathrm{~kg} / \mathrm{m}^{3}\right)$. A phenolphthalein $\mathrm{pH}$ indicator is used to determine the carbonation depth at 113 sampling points, and the average experimental carbonation depth $11.6 \mathrm{~mm}$ with a standard deviation of $2.45 \mathrm{~mm}$ [68].

Fig. 7 shows that Papadakis' model underestimates the carbonation depth whereas Yang's model overestimates it. Papadakis' and Yang's predictions are both outside standard deviations upper and lower limits. The meta-model predicted values, on the other side, are within a satisfactory range, close to the average value and within the standard deviation.

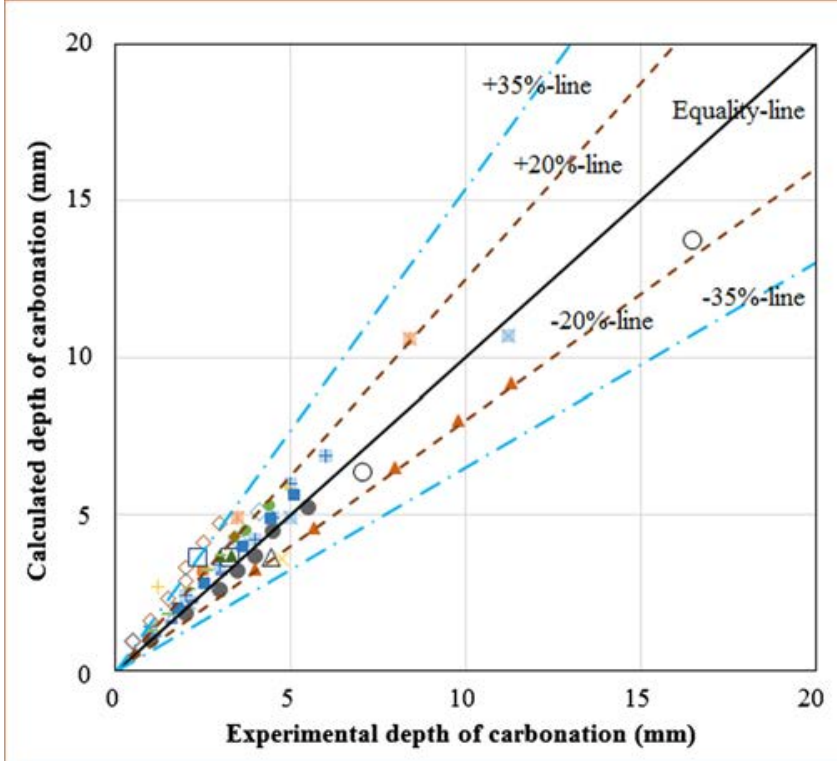

De Ceukelaire and Nieuwnburg (CEM III/A-S $32.5 \mathrm{~N}$ and $\mathrm{W} / \mathrm{B}=0.6$ )

= Chatveera et al. (CEM I $32.5 \mathrm{~N}$ and W/B $=0.6$ )

$\triangle$ Chatveera et al. (CEM I $32.5 \mathrm{~N}$ and $\mathrm{W} / \mathrm{B}=0.7$ )

Chatveera et al. (CEM I $32.5 \mathrm{~N}$ and $\mathrm{W} / \mathrm{B}=0.8$ )

$x$ Galan et al. (CEM I 42.5R and W/B $=0.45$ )

- Galan et al. (CEM I 42.5R and W/B =0.6)

+ Jones et al. (CEM III/A $32.5 \mathrm{~N}$ and W/B = 0.48)

Jones et al. (CEM I $32.5 \mathrm{~N}$ and $\mathrm{W} / \mathrm{B}=0.59$ )

- Jones et al. (CEM II/B $32.5 \mathrm{~N}$ and $\mathrm{W} / \mathrm{B}=0.46$ )

- Rozière et al. (CEM I $52.5 \mathrm{~N}$ and $\mathrm{W} / \mathrm{B}=0.63$ )

$\square$ Rozière et al. (CEM I $52.5 \mathrm{~N}, \mathrm{~W} / \mathrm{B}=0.63$ and $30 \% \mathrm{FA}$ )

$\triangle$ Rozière et al. (CEM I $52.5 \mathrm{~N}, \mathrm{~W} / \mathrm{B}=0.58$ and $30 \% \mathrm{FA}$ )

x Valcuende and Parra

(CEM II/B-M(V-LL) $32.5 \mathrm{~N}$ and $\mathrm{W} / \mathrm{B}=0.55$ )

* Valcuende and Parra

(CEM II/B-M(V-LL) $42.5 \mathrm{~N}$ and $\mathrm{W} / \mathrm{B}=0.55)$

Valcuende and Parra

(CEM II/B-M(V-LL) $32.5 \mathrm{~N}$ and $\mathrm{W} / \mathrm{B}=0.65$ )

Valcuende and Parra

(CEM II/B-M(V-LL) $42.5 \mathrm{~N}$ and W/B $=0.45$ )

Khunthongkeaw et al. (CEM I $52.5 \mathrm{~N}$ and $\mathrm{W} / \mathrm{B}=0.5$ )

- Khunthongkeaw et al. (CEM I $52.5 \mathrm{~N}, \mathrm{~W} / \mathrm{B}=0.5$ and $10 \% \mathrm{FA}$ )

- Khunthongkeaw et al. (CEM I 52.5N,W/B $=0.5$ and $30 \% \mathrm{FA}$ )

Khunthongkeaw et al. (CEM I $52.5 \mathrm{~N}, \mathrm{~W} / \mathrm{B}=0.5$ and $50 \% \mathrm{FA}$ )

Fig. 5. Comparison between calculated and experimental carbonation depths with different $W / C$ ratio and cement types 


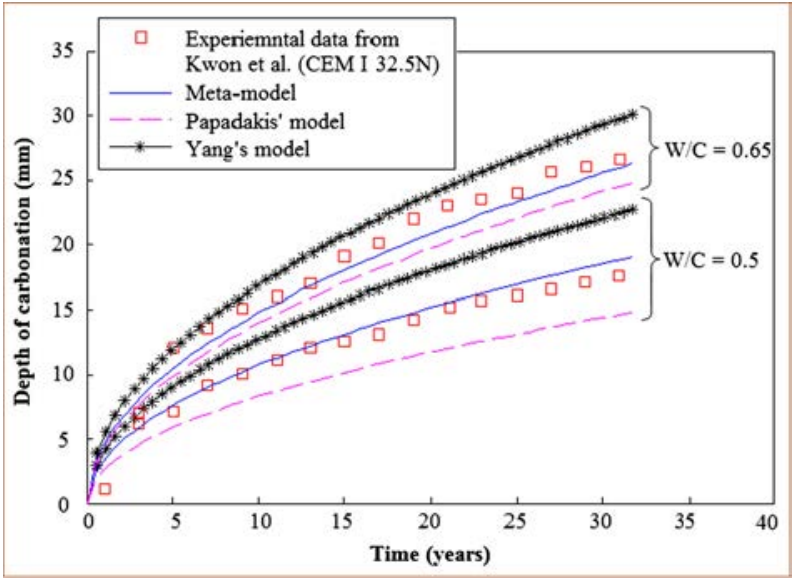

Fig. 6. Comparison between calculated and experimental carbonation depths with different $W / C$ ratios.

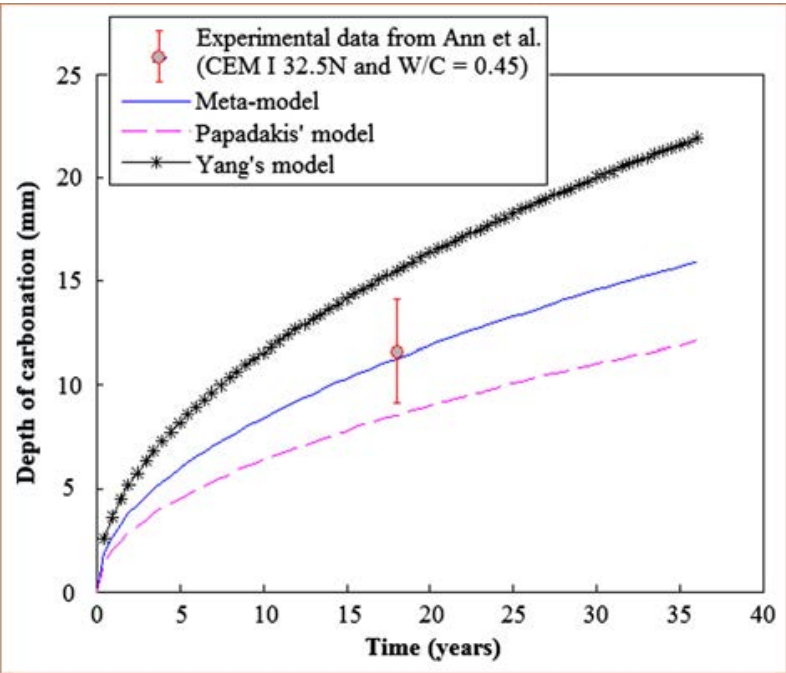

Fig. 7. Comparison between calculated and experimental carbonation depth results by Ann et al. [68]

In both cases studied here and in relation to the experimental results, Papadakis' $[4,25,27]$ and Yang's [11] models systematically underestimate or overestimate carbonation depth, respectively. Regarding service times on RC structures, e.g., maintenance repair strategies, etc., Yang's model [11] can be considered more secure.

\subsection{Comparison with all collected data (any cases material and environmental cases)}

All the data collected are used for comparison in this subsection: 153 carbonation depths measured on different materials, with different $t_{c}$ and under different environmental conditions. These experimental data are compared with the calculated carbonation depths obtained using the three models (the meta-model, Papadakis' model [4,25,27] and Yang's model [11]). Figs. 8-10, present the results of the different comparison, respectively. For each comparison, the determination coefficient, $R^{2}$, is calculated between the data and the line of equality. The $R^{2}$ value obtained for the meta-model indicates that the predictions satisfactorily agree with the measured data. Therefore, we can say that the carbonation depth in concrete can be reasonably estimated by the

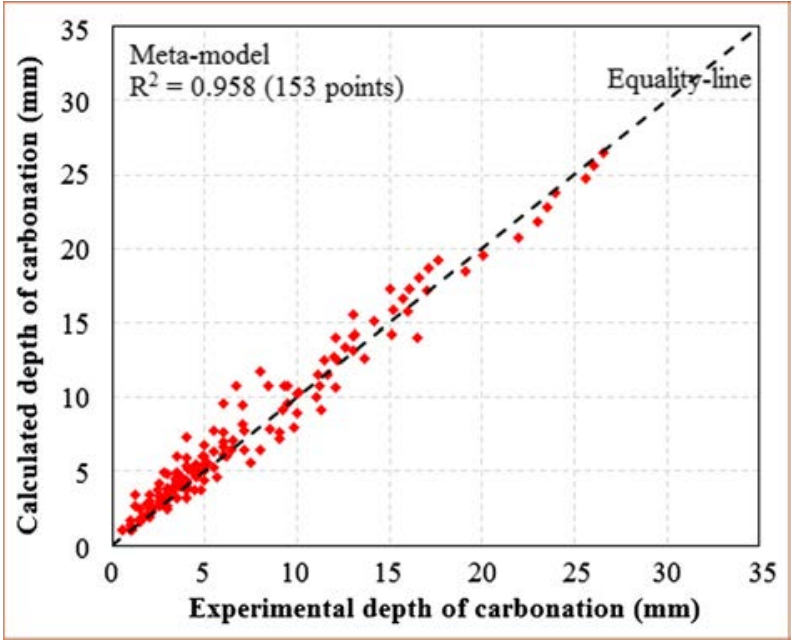

Fig. 8. Comparison between calculated and experimental carbonation depths using the meta-model.

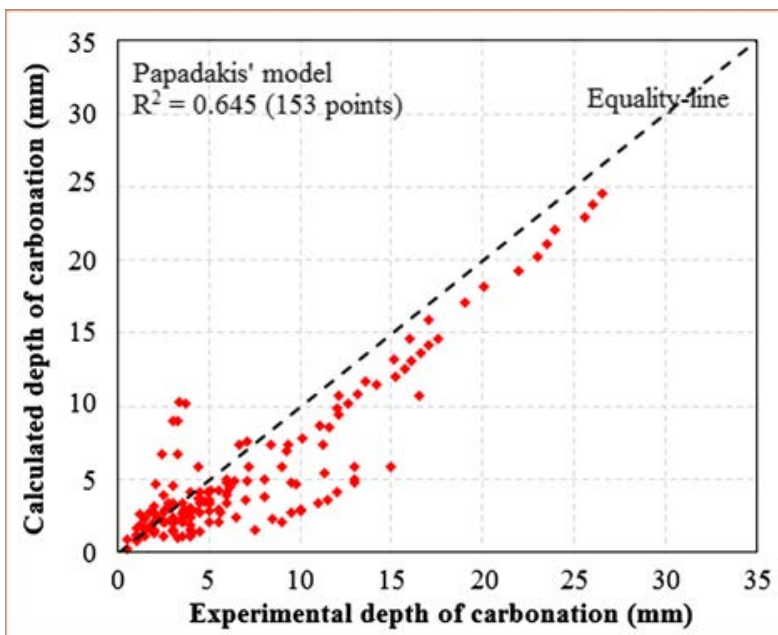

Fig. 9. Comparison between calculated and experimental carbonation depths using Papadakis' model.

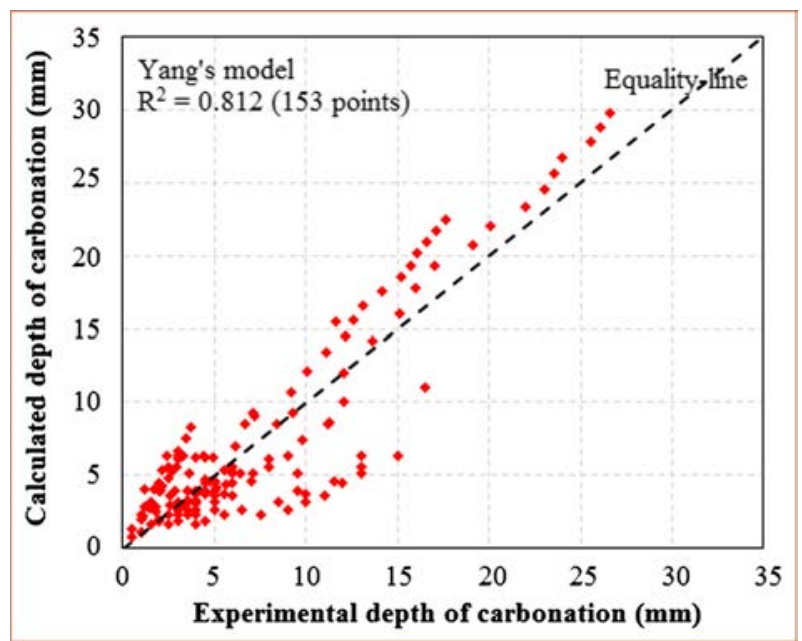

Fig. 10. Comparison between calculated and experimental carbonation depths using Yang's model. 
meta-model presented in this paper. Papadakis' and Yang's models may, on the other side, cannot be used against data collected for the experimental investigation carried out to determine the impact of $t_{c}$ on the carbonation rate like in Balayssac et al. [50]. The comparison results reveal that most of the data on the long-term are overestimated by Yang's model [11]. However, the prediction is more secure for reinforced concrete structures as regards maintenance strategies. Papadakis' model $[4,25,27]$, on the other hand, underestimates most of the data.

\section{Conclusion}

The aim of this paper was to present and validate generic model that can be easily used by civil engineers consider carbonation impact in the life cycle design of reinforced concrete structures. We thus have developed a semi-empirical model based on the analytic solution of Fick's first law, which includes as much engineering design options as possible.

The survey of the literature have revealed that: (i) the amount of $\mathrm{CO}_{2}$ absorbed is not only highly dependent on the cement content, but also on the cement clinker; (ii) the $\mathrm{CO}_{2}$-diffusion coefficient depends on many influencing parameters like the 28-day compression strength $\left(f_{c}\right)$, the concrete porosity, the water to cement ratio, the coarse aggregate content, the replacement percentage of mineral admixtures, the initial curing period, the ambient temperature and the relative external humidity. If some already available models account for some of these parameters, none of them include them all.

The meta-model predictions for carbonation depth are based on the analytic solution of Fick's first law and take into account many parameters readily available in the case of new reinforced structures. The validation of the meta-model has been conducted using data from literature on short and long-term natural carbonation exposure conditions for CEM I, CEM II, CEM III cement types, and CEM I additives (FA), and for a wide range of $W / C$ ratios, cement contents and exposure conditions. This new meta-model makes it possible to predict concrete carbonation depth for a wide range of curing time (between 1 and 28 days). The predictions obtained are satisfactorily accurate for different types of cement. The good agreement between the calculated carbonation depths and the experimental data found in the literature demonstrates that the meta-model predictions for concrete service life as regards carbonation are reasonably accurate and reliable.

Furthermore, the benefit of using semi-empirical models is that the stochastic nature of all the model parameters can be directly considered in a full probabilistic approach [3]. That is why we will conduct additional researches on the statistical analysis of the meta-model under stochastic variations in order to determine more effective levers for material durability as regards carbonation.

\section{Acknowledgements}

Funds for the research and education chair of civil engineering and eco-construction were provided by the Chamber of Trade and Industry of Nantes and Saint-Nazaire cities, the CARENE (urban agglomeration of Saint-Nazaire), Charier, Architectes Ingénieurs Associés, Vinci construction, the Regional Federation of Buildings, and the Regional Federation of Public Works. Donators had no involvement in the study design, the writing and the decision to submit this article. The authors would like to thank them all for their financial support.

\section{References}

[1] K. Tuutti, Corrosion of steel in concrete, Swed. Cem. Concr. Res. Inst. Stockh. (1982).

[2] E. Rozière, A. Loukili, F. Cussigh, A performance based approach for durability of concrete exposed to carbonation, Constr. Build. Mater. 23 (1) (Jan. 2009) $190-199$.

[3] fib CEB-FIP, Ed., Model code for service life design. Lausanne: fib, 2006.

[4] V.G. Papadakis, A reaction engineering approach to the problem of concrete carbonation, AIChE J. 35 (10) (1989) 1639-1650.

[5] Y.F. Houst, F.H. Wittmann, Depth profiles of carbonates formed during natural carbonation, Cem. Concr. Res. 32 (2002) 1923-1930.

[6] M.G. Alexander, J.R. Mackechnie, W. Yam, Carbonation of concrete bridge structures in three South African localities, Cem. Concr. Compos. 29 (10) (Nov. 2007) 750-759.

[7] L. Ying-Yu, W. Qui-Dong, The mechanism of carbonation of mortars and the dependence of carbonation on pore structure, ACI Mater. J. (1987) 1915-1943.

[8] R.F.M. Bakker, Model to calculate the rate of carbonation resistance of conrete under different climatic conditions, Rapp. CEMIJ Bv Lab. Imuiden Holl. (1993).

[9] L. Jiang, B. Lin, Y. Cai, A model for predicting carbonation of high-volume fly ash concrete, Cem. Concr. Res. 30 (2000) 699-702.

[10] N. Hyvert, A. Sellier, F. Duprat, P. Rougeau, P. Francisco, Dependency of C-S-H carbonation rate on $\mathrm{CO} 2$ pressure to explain transition from accelerated tests to natural carbonation, Cem. Concr. Res. 40 (11) (Nov. 2010) 1582-1589.

[11] K.-H. Yang, E.-A. Seo, S.-H. Tae, Carbonation and CO2 uptake of concrete, Environ. Impact Assess. Rev. 46 (Apr. 2014) 43-52.

[12] B.G. Salvoldi, H. Beushausen, M.G. Alexander, Oxygen permeability of concrete and its relation to carbonation, Constr. Build. Mater. 85 (Jun. 2015) 30-37.

[13] A.V. Saetta, The carbonation of concrete and the mechanism of moisture, heat and carbon dioxyde flow through porous materials, Cem. Concr. Res. 23 (1993) $761-772$.

[14] A.V. Saetta, 2-D model for carbonation and moisture/heat flow in porous materials, Cem. Concr. Res. 25 (8) (1995) 1703-1712.

[15] B. Bary, A. Sellier, Coupled moisture-carbon dioxide-calcium transfer mode for carbonation of concrete, Cem. Concr. Res. 34 (10) (Oct. 2004) 1859-1872.

[16] D.C. Park, Carbonation of concrete in relation to $\mathrm{CO} 2$ permeability and degradation of coatings, Constr. Build. Mater. 22 (11) (Nov. 2008) 2260-2268.

[17] N.I. Fattuhi, Carbonation of concrete as affected by mix constituents and initial water curing period, Mater. Struct. 19 (2) (1986) 131-136.

[18] N. R. Ravahatra, T. De Larrard, F. Duprat, E. Bastidas-Arteaga, F. Schoefs, Sensitivity analysis of simplified models of carbonation-extension in spatial variability-updating through Bayesian network, in: Proceedings of the 2nd International Symposium on Uncertainty Quantification and Stochastic Modeling, 2014.

[19] C.-F. Chang, J.-W. Chen, The experimental investigation of concrete carbonation depth, Cem. Concr. Res. 36 (9) (Sep. 2006) 1760-1767.

[20] S. Talukdar, N. Banthia, J.R. Grace, Carbonation in concrete infrastructure in the context of global climate change - Part 1: experimental results and model development, Cem. Concr. Compos. 34 (8) (Sep. 2012) 924-930.

[21] S. Talukdar, N. Banthia, J.R. Grace, S. Cohen, Carbonation in concrete infrastructure in the context of global climate change: Part 2 - Canadian urban simulations, Cem. Concr. Compos. 34 (8) (Sep. 2012) 931-935.

[22] M. Thiery, G. Villain, P. Dangla, G. Platret, Investigation of the carbonation front shape on cementitious materials: effects of the chemical kinetics, Cem. Concr. Res. 37 (7) (Jul. 2007) 1047-1058.

[23] H. Klopfer, The carbonation of external concrete and the control of it, Bautenschutz Bausanier. 1 (3) (1978) 86-97.

[24] R.J. Millington, Gas diffusion in porous media, Science 130 (1959) 100-102.

[25] V.G. Papadakis, C.G. Vayenas, M.N. Fardis, Physical and chemical characteristics affecting the durability of concrete, ACI Mater. J. 88 (2) (1991).

[26] Y.F. Houst, F.H. Wittmann, Influence of porosity and water content on the diffusivity of $\mathrm{CO} 2$ and $\mathrm{O} 2$ through hydrated cement paste, Cem. Concr. Res. 24 (6) (1994) 1165-1176

[27] V.G. Papadakis, Effect of supplementary cementing materials on concrete resistance against carbonation and chloride ingress, Cem. Concr. Res. 30 (2) (2000) 291-299.

[28] L. Basheer, P.A.M. Basheer, A.E. Long, Influence of coarse aggregate on the permeation, durability and the microstructure characteristics of ordinary Portland cement concrete, Constr. Build. Mater. 19 (9) (Nov. 2005) 682-690.

[29] V.G. Papadakis, M.N. Fardis, C.G. Vayenas, Effect of composition, environmental factors and cement-lime mortar coating on concrete carbonation, Maerials Struct. 25 (1992) 293-304.

[30] H.-W. Song, S.-J. Kwon, K.-J. Byun, C.-K. Park, Predicting carbonation in earlyaged cracked concrete, Cem. Concr. Res. 36 (5) (May 2006) 979-989.

[31] H. Al-Khaiat, N. Fattuhi, Carbonation of concrete exposed to hot and aric climate, J. Mater. Civ. Eng. 14 (2) (2002) 97-107.

[32] P. Sulapha, S.F. Wong, T.H. Wee, S. Swaddiwudhipong, Carbonation of concrete containing mineral admixtures, J. Mater. Civ. Eng. 15 (2) (2003) 134-143.

[33] H.-W. Song, S.-J. Kwon, Permeability characteristics of carbonated concrete considering capillary pore structure, Cem. Concr. Res. (Jun. 2007) 909-915.

[34] L.J. Parrott, A review of carbonation in reinforced concrete, 1987.

[35] V.G. Papadakis, Effect of fly ash on Portland cement systems: Part I. Lowcalcium fly ash, Cem. Concr. Res. 29 (11) (1999) 1727-1736. 
[36] V.G. Papadakis, Effect of fly ash on Portland cement systems: Part II. Highcalcium fly ash, Cem. Concr. Res. 30 (10) (2000) 1647-1654.

[37] G.J. Osborne, Durability of Portland blast-furnace slag cement concrete, Cem. Concr. Compos. 21 (1999) 11-21.

[38] X.-Y. Wang, H.-S. Lee, A model for predicting the carbonation depth of concrete containing low-calcium fly ash, Constr. Build. Mater. 23 (2) (Feb. 2009) 725733.

[39] J. Khunthongkeaw, S. Tangtermsirikul, T. Leelawat, A study on carbonation depth prediction for fly ash concrete, Constr. Build. Mater. 20 (9) (Nov. 2006) 744-753.

[40] K. Sisomphon, L. Franke, Carbonation rates of concretes containing high volume of pozzolanic materials, Cem. Concr. Res. 37 (12) (Dec. 2007) $1647-$ 1653.

[41] A. Younsi, P. Turcry, E. Rozière, A. Aït-Mokhtar, A. Loukili, Performance-based design and carbonation of concrete with high fly ash content, Cem. Concr. Compos. 33 (10) (Nov. 2011) 993-1000.

[42] X. Zhang, X. Zhou, H. Zhou, K. Gao, Z. Wang, Studies on forecasting of carbonation depth of slag high performance concrete considering gas permeability, Appl. Clay Sci. 79 (Jul. 2013) 36-40.

[43] H. Shi, B. Xu, X. Zhou, Influence of mineral admixtures on compressive strength, gas permeability and carbonation of high performance concrete, Constr. Build. Mater. 23 (5) (May 2009) 1980-1985.

[44] V.G. Papadakis, Experimental investigation and mathematical modeling of the concrete carbonation problem, Chem. Eng. Sci. 46 (5/6) (1991) 1333-1338.

[45] I.-S. Yoon, O. Çopuroğlu, K.-B. Park, Effect of global climatic change on carbonation progress of concrete, Atmos. Environ. 41 (34) (Nov. 2007) 7274 7285.

[46] M.G. Stewart, P. Jianxin, Life-cycle cost assessment of climate change adaptation measures to minimise carbonation-induced corrosion risks, Int. J. Eng. Uncertainty Hazards Assess. Mitig. 2 (2010) 35-46.

[47] Y.F. Houst, P.E. Roelfstra, F.H. Wittmann, A model to predict service life of concrete structures, Mater. Sci. Restor. (1983) 181-186.

[48] N.I. Fattuhi, Concrete carbonation as influenced by curing regime, Cem. Concr. Res. 18 (3) (1988) 426-430.

[49] K. Tan, O.E. Gjorv, Performance of concrete under different curing conditions, Cem. Concr. Res. 26 (3) (1996) 355-361.

[50] J.P. Balayssac, C.H. Détriché, J. Grandet, Effects of curing upon carbonation of concrete, Constr. Build. Mater. 9 (2) (1995) 91-95.

[51] V.G. Papadakis, C.G. Vayenas, M.N. Fardis, Fundamental modeling and experimental investigation of concrete carbonation, Mater. J. 88 (1991) $363-$ 373.

[52] C. Pade, M. Guimaraes, The CO2 uptake of concrete in a 100 year perspective Cem. Concr. Res. 37 (9) (Sep. 2007) 1348-1356.

[53] EN 197-1, Cement-Part 1: composition, specifications and conformity criteria for common cements, 2002
[54] V.G. Papadakis, S. Demis, 'Estimation and validation of concrete strength and service life using software packages based on predictive models, in: Proceedings of the 12th international conference on durability of building materials and components, Porto Portugal, 2011.

[55] Y. Yuan, J. Jiang, Prediction of temperature response in concrete in a natural climate environment, Constr. Build. Mater. 25 (8) (Aug. 2011) 3159-3167.

[56] P.A.M. Basheer, F.R. Montgomery, A.E. Long, et al., Factorial experimental design for concrete durability research, Proc. ICE-Struct. Build. 104 (4) (1994) 449-462.

[57] G. Villain, M. Thiery, Gammadensimetry: a method to determine drying and carbonation profiles in concrete, NDT E Int. 39 (4) (Jun. 2006) 328-337.

[58] S. Demis, M.P. Efstathiou, V.G. Papadakis, Computer-aided modeling of concrete service life, Cem. Concr. Compos. 47 (Mar. 2014) 9-18.

[59] SP 23: 1982, Handbook on concrete mixes, Bureau of indian standards, 1990.

[60] V.G. Papadakis, Experimental investigation and theoretical modeling of silica fume activity in concrete, Cem. Concr. Res. 29 (1) (1999) 79-86.

[61] M. Valcuende, C. Parra, Natural carbonation of self-compacting concretes, Constr. Build. Mater. 24 (5) (May 2010) 848-853.

[62] M.R. Jones, M.D. Newlands, A.M.O. Abbas, R.K. Dhir, Comparison of 2 year carbonation depths of common cement concretes using the modified draft CEN test, Mater. Struct. 34 (7) (2001) 396-403.

[63] Z.P. Bažant, L.J. Najjar, Nonlinear water diffusion in nonsaturated concrete, Mater. Constr. 5 (1) (1972) 3-20.

[64] O.-P. Kari, DuraInt Report-Task 4-Deterioration Models with Interaction, Aalto University, RESEARCH REPORT AALTO-R-001-11, 2011.

[65] W. Lu, H. Guo, IM. Chou, R.C. Burruss, L. Li, Determination of diffusion coefficients of carbon dioxide in water between 268 and $473 \mathrm{~K}$ in a highpressure capillary optical cell with in situ Raman spectroscopic measurements, Geochim. Cosmochim. Acta 115 (Aug. 2013) 183-204.

[66] I. Galan, C. Andrade, P. Mora, M.A. Sanjuan, Sequestration of CO2 by concrete carbonation, Environ. Sci. Technol. 44 (8) (2010) 3181-3186.

[67] B. Chatveera, P. Lertwattanaruk, Durability of conventional concretes containing black rice husk ash, J. Environ. Manage. 92 (1) (Jan. 2011) 59-66.

[68] K.Y. Ann, S.-W. Pack, J.-P. Hwang, H.-W. Song, S.-H. Kim, Service life prediction of a concrete bridge structure subjected to carbonation, Constr. Build. Mater. 24 (8) (Aug. 2010) 1494-1501.

[69] S.-J. Kwon, S.-S. Park, S.-H. Nam, A suggestion for carbonation prediction using domestic field survey data of carbonation, J. Korea Inst. Struct. Maint. Inspection 11 (5) (2007) 81-88.

[70] L. De Ceukelaire, D. Van Nieuwenburg, Accelerated carbonation of a blastfurnace cement concrete, Cem. Concr. Res. 23 (1993) 442-452.

[71] VDZ Activity Report, Performance of cement, 2005-2003.

[72] Musa yapi, <http://www.musayapi.com.tr> 